\title{
Can austerity work?
}

\author{
Alfredo Calcagno* \\ Head, Macroeconomic and Development Policies Branch, United Nations Conference on Trade and \\ Development (UNCTAD)
}

\begin{abstract}
Economic policies in several major countries have shifted from fiscal stimulus to austerity in the last few years. They seek to reduce fiscal deficits and reverse the increasing trend of public debt mainly through immediate spending cuts. The fact that fiscal austerity is applied simultaneously in these countries adds to its negative impact on economic recovery. Austerity policies are based on a wrong diagnosis of the nature and depth of the crisis, and also on erroneous views of economic mechanisms. This is a financial crisis due to private over-indebtedness and financial deregulation, not a crisis caused by fiscal profligacy: austerity focuses on a symptom of the crisis, not on its causes. With high unemployment and the ongoing de-leveraging process, private demand tends to remain subdued for a prolonged period and will not be stimulated by monetary expansion alone. If in addition governments tighten fiscal policies, demand and growth will be further compressed, fiscal revenues will decline, expected fiscal consolidation will remain elusive and so will the recovery of investors' confidence, which many see as the key to restoring growth. Only a recovery of growth, with nominal GDP expanding at rates higher than interest rates in the medium and long run will abate debtto-GDP ratios. That growth can result from coordinated supportive policies, which may include changes in the level and composition of public income and expenditure and a better distribution of income and credit, which would expand fiscal multipliers and the purchasing power of low and medium income groups with a high propensity to consume.
\end{abstract}

Keywords: austerity, financial crisis, multipliers, debt, confidence, macroeconomic policy

JEL codes: E44, E51, E61, E62, E63, E64, G01, H63

\section{INTRODUCTION}

When the financial and economic crisis broke in September 2008, governments in almost all major countries, both developed and emerging, massively supported their economies. According to their degree of urgency, they rescued their financial systems from the risk of a complete collapse and/or expanded public expenditure in order to replace the brutal contraction of private demand. Monetary authorities reduced policy interest rates to historical lows and provided unlimited amounts of liquidity in response to the sudden interruption of interbank financing. In several cases, they went beyond their traditional mandate by directly supporting governments and even the private sector. All these policies were applied simultaneously in the different countries; to what extent this was the fruit of deliberate policy coordination or the result of the same problems affecting all these countries at the same time may be disputable.

* The views expressed in this paper are the author's only and need not reflect, and should not be represented as, UNCTAD views. 
Nonetheless, the result was the same: all countries benefited from each other's stimulus, and the fall in GDP and international trade was severe but relatively short, especially in developing countries. In addition, the evidence of economic interdependence and of positive synergies gave a new impetus to international economic cooperation initiatives like the G20.

At that time, the blame for the crisis was put on the financial system, and policy proposals accordingly pointed to a radical reform that would not only reinforce financial supervision but would also change substantially the functioning and role of the financial sphere in the economy. At their London meeting in April 2009, the G20 leaders made a commitment to strengthen financial supervision and regulation as the key to recovering confidence.

These policy intentions began to fade, however, as soon as most countries recovered positive growth rates in the second half of 2009. With the sense of having avoided the worst, the focus was reoriented from the reform of the financial system to the adjustment of public accounts. Hence, even if in the Toronto Summit Declaration (June 2010) the G20 leaders called for further financial sector reforms, they then viewed fiscal consolidation as the necessary condition for recovering confidence and sustaining growth (G20 2010). Accordingly, advanced economies committed themselves to quantitative targets for reducing fiscal deficits (by 2013) and public debt-to-GDP ratios (by 2016). Austerity became the watchword.

\section{THE GARDEN OF FORKING PATHS}

Economic policy was at a crossroads, as policymakers had to choose between two options: to sustain the still modest and fragile economic recovery with expansionary policies that should promote employment; or to undertake fiscal adjustment to cope with public deficits and debt levels viewed as excessively high that could undermine the confidence of financial markets and prompt a new financial crisis. However, it seems more appropriate to describe that situation as a 'garden of forking paths', as in Borges' short story, as policymakers faced not just one but a succession of choices.

The first policy choice taken by the economic authorities, particularly in developed countries, was reducing public debt-to-GDP ratios. For sure, the crisis had significantly increased fiscal deficits and debt ratios in many developed countries, partly due to 'automatic stabilizers' (including lower tax revenues and higher public transfers to the unemployed) and partly to extraordinary measures, such as financial bail-outs, tax cuts and stimulus expenditure packages. This did not necessarily mean that consolidating fiscal accounts had to be the policy priority. However, policymakers considered that debt ratios were approaching or had already reached a level in which solvency was at risk (IMF 2010a, pp. 4-5; Ostry et al. 2010). It was thus necessary to send strong signals of a future reversal in the trend of public debt ratios, in order to maintain investors' confidence and avoid a self-fulfilling prophecy on sovereign debt insolvency, in which rising risk premiums would deteriorate fiscal balances and jeopardize the roll-over of maturing debt.

A second choice is how to reduce the debt-to-GDP ratio, by reducing the numerator (the debt), increasing the denominator (GDP), or by some combination of both. In this choice, time horizon is essential. The strategy of abating high indebtedness through GDP growth (and rising public revenues) normally takes decades rather than years, as was the case in several combatant countries after the Second World War. The key was a nominal GDP growing at a rate higher than that of interest rates; debt ratios declined sharply even if the stock of debt did not. The alternative (reducing debt) is 
in general much more costly. Historically, debts could be rapidly reduced through hyperinflations or extended bankruptcies; in the case of states, bankruptcies have been substituted by debt repudiation or restructuring with sizeable 'haircuts' (Aglietta 2012; Krugman 2012). At this juncture, policymakers chose to focus on the debt (the numerator), generally not for reducing it in nominal terms (except in Greece), but to curb its rise in the short run through fiscal tightening, even if this is costly in terms of GDP growth. Different but converging views seem to have motivated this choice: some thought that global economic recovery was solid enough and did not need further fiscal stimulus in advanced economies; proponents of the 'expansionary fiscal adjustment' considered that fiscal tightening would boost confidence and consequently growth; or, less enthusiastically, others admitted that 'fiscal consolidation typically causes short-term contractionary effects' (Bornhorst et al. 2010, p. 7; see also IMF 2010b), but such costs are assumed to be moderate and temporary, and to be much lower than the long-term costs, which allegedly would otherwise materialize.

The third choice is how to improve the fiscal balance, by reducing spending or by increasing taxes. This option is frequently influenced by preferences related to the size and the role of the state: those who support its active role in income redistribution will opt for tax increases, especially if it reinforces progressive taxation; while those with opposing preferences will support expenditure cuts. However, the debate mostly focused on which kinds of measures would be more 'growth friendly', or less detrimental to growth. Studies of fiscal multipliers (see section 5 below) show that the impact of a change in public spending on GDP growth is higher than the effect of a change in taxes, because all the spending goes to global demand, while only part of the income devoted to tax payments is taken from consumption or investment, since another part would have been saved. Consequently, the best option should be raising taxes. However, the IMF elaborated an alternative view, which leads to the opposite recommendation. Using its Global Integrated Monetary and Fiscal Model, the IMF found that an adjustment through reduced spending would be less contractionary than an adjustment through tax increases. The difference does not result from dissimilar multipliers associated with higher taxes or lower spending, but from the assumption that Central Banks follow different policies in each case: they would be reluctant to reduce interest rates when fiscal tightening consists of increasing taxes, because higher indirect taxes would raise prices; but spending cuts are 'typically' accompanied by a large dose of monetary stimulus, which lowers the interest rate, causes a depreciation of the currency and generates net exports (IMF 2010b; for a more detailed critical analysis, see UNCTAD 2011, pp. 60-61). Hence, IMF calculations that show a relatively low cost of fiscal adjustment in terms of GDP growth ('fiscal consolidation equal to 1 per cent of GDP typically reduces real GDP by about 0.5 per cent after two years') do not measure the impact of the adjustment itself; rather, they compare the impact of a package composed of a spending-based fiscal adjustment plus monetary expansion, along with a net increase in exports, with the effect of a rise in taxes with tougher monetary policy. The dice are loaded. And here again, the choice of policymakers and IFIs is the most costly in terms of growth - fiscal tightening based on expenditure cuts rather than tax increases.

Finally, which spending should be cut? Recent OECD publications show that spending cuts essentially affect public salaries and employment, as well as expenditure on welfare, health care and pensions. And when fiscal tightening raises taxes, these basically involve indirect taxes (OECD 2011). Hence, fiscal adjustment has regressive distributional effects, mainly reducing the disposable income of lower income groups (that is, those with higher consumption propensities). 
In Borges' short story, at each fork the main character had to take the left path for attaining his destination. Here, at every fork, policymakers' choice seems to be the most costly in terms of GDP growth and employment.

These policy choices are leading advanced economies to an impasse. The search for fiscal consolidation stifled the economic recovery; as a consequence, fiscal imbalances could not be reabsorbed and public debt ratios kept growing. Confidence, which was expected to make the private sector restart credit, investment and consumption, did not materialize. Governments appeared to have little policy space (for partly selfinflicted reasons): on the fiscal side they adopted fiscal rules that greatly accentuated their contractionary stance, and on the monetary side they had little room for further reducing interest rates. Unconventional monetary measures, such as quantitative easing, have not resuscitated credit to the private sector; at best, they lowered long-term interest rates and prevented a liquidity crisis in a situation characterized by the scarcity of interbank credit. Hopes for economic stimulus are then placed on structural reforms, which are supposed to restore competitiveness, efficiency and, consequently, growth. Much pressure is also placed on trade partners, asking them to appreciate their currencies and expand their demand. This cannot be a general solution, since all the countries cannot improve their competitiveness at the same time, and surplus emerging economies cannot compensate for faltering demand in advanced economies. And to make things worse, the status quo does not seem to be an option either, because without a recovery, a twin (fiscal and financial) crisis will be very difficult to avoid: an increasing number of governments have problems financing their deficits and refinancing their debts, and fragile banks that have not been able to absorb their bad loans to the private sector now face the deterioration of their public bonds portfolios. Higher risk premiums raise interest rates and, together with the economic recession, may push an increasing number of actors into insolvency.

\section{WRONG DIAGNOSIS AND THE CONFIDENCE GAME}

A necessary condition for an appropriate response to the present economic crisis is to provide an accurate diagnosis of its causes, its nature and its depth. It must remind us that the financial crisis was caused by excessive borrowing and spending by the private sector in several countries, associated with a highly leveraged and unregulated financial system and with the generation of speculative bubbles; and that it was not the result of government profligacy. In virtually all the crisis-hit countries - with the notable exception of Greece government savings were positive or close to equilibrium before the crisis. Between 2002 and 2007-2008, fiscal balances improved significantly in most countries; on average, Africa, West Asian and CIS countries obtained fiscal surpluses on the eve of the crisis, while fiscal accounts in the rest of Asia and Latin America were roughly balanced. Even in the developed countries fiscal deficit had fallen to around 1.5 per cent of the GDP on average. By 2007, aggregate debt-to-GDP ratios of high, medium and low income countries were all on a declining trend (UNCTAD 2011, chapter II). High fiscal deficits and rapidly increasing debt ratios were the consequence of the crisis, but only in developed economies: in most developing and transition economies, the debt-to-GDP ratio resumed its downward trend with the recovered growth and, in many cases, new gains from the terms of trade. Hence, fiscal austerity addresses the symptom rather than the cause of the crisis (Aglietta 2011, p. 47). And even the symptom is far from general.

Yet fiscal tightening became an almost universal recommendation. As early as May 2010 , the IMF stated that 'fiscal strategies should aim at gradually - but steadily and 
significantly - reducing public debt ratios' (IMF 2010a, p. 4) - a call that was echoed in the G20 Toronto Declaration the following month, and reaffirmed in all subsequent G20 Summits (G20 2010; 2011). In the first half of 2011, after almost 2 years of satisfactory global economic growth (although several major economies had not yet recovered their pre-crisis GDP), the IMF deemed that the time for fiscal consolidation had come for everyone. In its view, the risk of a double-dip recession had to be dismissed, since private demand was already recovering on a sustainable basis and replacing public demand. Hence, developed countries had to address the more stringent risk of a confidence crisis, by tightening fiscal policies. At the same time, developing countries had to discontinue fiscal stimulus to avoid overheating, avert inflationary pressures and rebuild fiscal buffers. And even countries that could not resort to fiscal stimulus in 2008-2010 because they were already applying IMF-sponsored programmes when the crisis broke had to intensify their fiscal adjustments (IMF 2011a).

The optimistic view of a private sector 'taking the baton' of domestic demand overlooked the very nature of a financial crisis, in which both creditors and debtors seek to restore their balance sheets. Historical experience shows that financial crises take time to be reabsorbed: highly indebted, the private sector restrains consumption and investment demand, as private agents try (or are forced) to repay their debts. At the same time, banks seek to increase their capital/assets ratio, restraining the delivery of fresh credit to the private sector and trying to recover their loans. This is a classical 'debt-deflation' situation, already studied by Irving Fisher (1933), and more recently by Richard Koo (2011). In such a situation, the economy may be caught in a downward spiral. As they try to repay their debts, debtors cut their expenditure and try to sell their assets. Such actions tend to depress economic activity by lowering demand, and further reduce the prices of the assets, some of which may have been bought at credit and be part of the origin of the financial bubble and subsequent over-indebtedness. As a result, the fact that many debtors try to reimburse their debts at the same time undermines the repayment capacity of each of them. Simultaneously, banks accentuate this deflationary pressure by cutting their credit supply in the face of higher perceived risk. This is partly the normal reluctance to keep lending to an already highly-indebted customer (Kalecki's 'principle of growing risk'), and partly the result of the pro-cyclical bias of current banking regulation. In fact, the well-known pro-cyclical nature of finance has been reinforced by the Basel II rules, that minimize the need for capital during booms (when assets are seen as less risky, and hence call for lower capital requirement) and increase it during crises, when suddenly all assets are riskier than they were a few months earlier. As credit supply restrictions add weight to global demand, it is even more difficult for debtors to pay and for banks to recover their credits; this leads to supplementary requirements for bank recapitalization, etc.

This process of 'de-leveraging' comes in addition to other factors constraining demand in the developed economies, in particular high levels of unemployment and policies of wage compression. In such a situation, monetary policy is unable to restart growth: it is like 'pushing into a string'. The problem is not insufficient liquidity constraining credit supply: astronomic amounts of financing by the central banks have been put at the disposition of the banking system. In the United States, the Federal Reserve has injected more than $\$ 2$ trillion since September 2008, trebling its total assets; in the same period, the European Central Bank has doubled its assets to around 3 trillion euros. Still, banking credit to the private sector stagnated in Europe and decreased by 4 per cent in the United States between the third quarter 2008 and the end of 2011. If banks are not expanding their lending to the private sector it is not because they cannot, it is because either they do not want to (that is, they prefer to consolidate 
their balance sheets) or because the private sector does not demand net credit (that is, credit in addition to rolling-on maturing debts) as it does not intend to expand its consumption or investment.

Consequently, the strategy of recovering the confidence of the financial markets as the way to revive growth is doomed to failure, since even if their confidence could be restored in an economy that is going deeper into recession - which is highly unlikely it would not reverse de-leveraging forces and restart credit expansion.

The 'confidence game' has nonetheless been played again and again in all the financial crises in the emerging economies since the 1980s. It consisted of taking macroeconomic measures that "may not make sense in and of themselves but that policymakers believe will appeal to prejudices of investors' (Krugman 1998; see also Bresser-Pereira 2001). Such measures are invariably pro-cyclical. They generally seek to generate surpluses in the balance of payments and the fiscal primary balance in order to reassure domestic and foreign investors with regard to the willingness and capacity of repaying debts. When they are taken in the context of an IMF-backed programme, which is frequently the case, the debtor government can already pay part of its debt obligations with the new credits from official sources, without waiting for the results expected from economic adjustment.

The main logic of these programmes has not changed since 1952, when the first standby agreement was signed: the IMF provided a short-term credit for addressing a balanceof-payment imbalance, subject to policy conditions aimed at adjusting that imbalance and warranting the credit repayment. The basic conditions consist of tighter fiscal and monetary policies that reduce the aggregate demand. The conceptual framework for such policies is related to the 'absorption approach' - that is, the view that current account deficits result from a level of 'absorption' (domestic demand of consumption and investment) in excess of total output. Since the mid-1970s, when the IMF introduced the 'Extended Financial Facilities' (followed by the 'Enhanced Structural Adjustment Facilities' and the 'Poverty Reduction and Growth Facility'), the IMF conditionality incorporated structural reforms, in addition to macroeconomic adjustments, in order to obtain a lasting solution. The reforms are aimed at 'reducing government-imposed distortions and other structural and institutional rigidities that impair an efficient allocation of resources in the economy and hinder growth' (Mussa and Sevastano 1999, p. 22). According to the IMF economic classification, structural conditions may be distributed in three groups: 'economic management', which involves measures like improving the taxation system and widening the tax base, or strengthening public expenditure management; 'economic vulnerabilities', which includes reinforcing prudential regulations and financial sector supervision; and 'economic flexibility and efficiency', with measures like privatisation of state-owned enterprises, labour flexibility, agricultural market reforms and price deregulation (IMF 2001). As is readily apparent, the conditions requested by the 'troika' (IMF, European Central Bank and European Commission) to European countries seeking financial support result from rather long experience.

Pleasing the markets has proved to be a hard task, since 'markets appear somewhat schizophrenic - they ask for fiscal consolidation but react badly when consolidation leads to lower growth' (IMF 2012a, p. xiv). Logically this should lead to admitting the failure of the 'confidence game' and to reorienting economic policies without following investors' inconsistent prejudices. This has not happened (yet). It is now increasingly admitted that the rescue packages and adjustment programmes may not revive growth by influencing investors' (complicated) psychology, but they must nevertheless be applied because they can 'gain time' for structural reforms, which will provide the basis for solid and lasting growth. The rationale may change, but the policy recommendations remain 
the same. To what extent these measures, including structural reforms, will eventually lead to growth is debatable; what is indisputable is that the time 'gained' is used by private banks for reducing their exposure - exactly as they did between 1982 and 1985 in Latin America. According to BIS statistics, international banks have already reduced their exposure to 'GIPSI' countries (Greece, Ireland, Portugal, Spain and Italy) from $\$ 3628$ billion in the second quarter 2008 to $\$ 1581$ billion in the last quarter of 2011. The amount of the debt does not diminish in those countries; what changes are the creditors, as private banks are replaced by the IMF, the European Central Bank, the European Stability Mechanism, foreign governments, etc. As a result, the confidence game comes to an end without the players whose confidence was supposed to matter.

\section{GOALS AND MECHANISMS}

Divergences in policy recommendations do not result only (or mainly) from opposing goals, as everyone supports the return to growth and sustainable fiscal and external balances. Disagreements result from different diagnoses and views on how the economy works. Although the United Nations Conference on Trade and Development (UNCTAD) and Department on Economic and Social Affairs (UNDESA) have repeatedly warned against premature fiscal adjustment, this does not indicate that the UN Secretariat is against fiscal consolidation. In the view of these institutions, fiscal consolidation is the result of a process of sustained growth (which requires supportive economic policies), and not its precondition (see UNCTAD 2008-2012; UNDESA/UNCTAD/Regional Commissions 2008-2012).

There is a significant misunderstanding, perhaps deliberate, around the notion of 'fiscal consolidation', as policy measures are not clearly differentiated from policy outcomes. Fiscal austerity is a policy measure; fiscal consolidation is the goal that may or may not be achieved through fiscal austerity; yet 'fiscal consolidation' is used with both meanings, as if the desired outcome from policy tightening was assured. However, many factors can mediate and have an impact on the economic result. One basic point, discussed in the previous section, is the nature and depth of the crisis. If slow growth or recession is due to insufficient demand, a new round of fiscal tightening will further depress the economic activity. As a result, it will reduce tax revenues and increase the social expenditure; but there is no guarantee that, all in all, fiscal balance will improve. Low growth will also affect the debt-to-GDP ratio by weakening GDP (the denominator). Furthermore, by extending or deepening the recession, larger parts of the financial system may need government support, which would cause dramatic deterioration of the fiscal accounts. Conversely, by strengthening the domestic demand, fiscal stimulus may actually contribute to fiscal consolidation.

The implicit identification of fiscal tightening and fiscal consolidation shows the lack of a macroeconomic approach. It tends to identify government accounts with those of a household that can equilibrate its budget by cutting expenses at a given level of revenue. This leads to the frequent call to avoid a country 'living above its means', but forgets that government expenditure and revenues are linked together. A government can target a fiscal balance, it cannot just decree it, in the same way that a firm cannot decide the level of its profits; and even households, if many of them tried to increase their savings at the same time, would fall short of their goals because they would be reducing global demand and with it their own revenues, since one agent's expenditure is another agent's income. In other terms, savings made by governments, firms and households are all 
endogenous variables, which are influenced by their decisions, but not always in the way they expect.

This is not understood when a rigid level (or ceiling) of fiscal deficit is incorporated into the law, or even into the constitution of some states or countries. The intention is to gain credibility by showing an inflexible commitment to fiscal discipline, but the loss of flexibility in macroeconomic administration may lead to the opposite result. A striking example was the 'Zero-deficit Act', adopted in July 2001 in Argentina as a way of handling the ongoing recession, which a few months later led to the collapse of the currency board (the 'convertibility' regime). The Act intended to ban any fiscal deficit and ensure the servicing of the public debt by automatically adjusting primary fiscal expenditure (excluding interest payments) to current fiscal income. The idea was to recover the confidence of financial markets in the government's solvability, with the expectation of strongly reducing interest rates, attracting new capital and recovering economic growth. The law established that, if government revenues fell short of budgeted expenditure, a general cut would affect all public expenditure at the rate needed for balancing fiscal accounts. A 13 per cent cut was immediately applied to publicservant salaries, pensions and other payments. The impact on economic activity was devastating. In the third and fourth quarters, seasonally adjusted real GDP plummeted by 4.7 and 5.7 per cent vis-à-vis the previous quarter (more than 20 per cent at the annual rate), and tax revenues fell by 8 and 25 per cent respectively, compared to the same period in the previous year. Needless to say, fiscal accounts did not equilibrate through the Zero-deficit Act; fiscal consolidation resulted from a complete change of policies and the rapid growth which was achieved with strong increases in both public expenditure and revenues, among other factors.

The IMF, who strongly supported the Zero-deficit Act in Argentina, has an impressive record of misjudgments in relation to the expected outcome of fiscal adjustments. The IMF's Independent Evaluation Office examined 133 IMF-supported programmes in 70 countries and noted 'a tendency to adopt fiscal targets based on overoptimistic assumptions about the pace of economic recovery leading inevitably to fiscal underperformances' (IMF 2003, p. vii).

Figure 1 compares short-term forecasts included in the letters of intention (LOI) by crisis-hit countries with the actual results of the IMF-supported programme. Two periods are examined: financial crisis in emerging economies in the late 1990s and the present financial crisis. LOI forecasts of GDP growth and general government balances are shown on the horizontal axis, and actual values are presented on the vertical axis. It appears that almost all the countries are located to the right-hand side of a 45 degree line, showing that outcomes were systematically below expectations: the rates of GDP growth and the level of fiscal consolidation that were expected as a result of the prescribed austerity were overestimated, sometimes very significantly. The two exceptions were the Russian Federation in 1999 and Iceland in 2009 - that is, the two countries that did not comply with the signed LOI, as they defaulted (UNCTAD 2011, pp. 63-65).

Such a systemic bias stems from a fundamental macroeconomic misconception. It was assumed that the private sector would immediately compensate for any reduction of public expenditure, as 'fiscal contraction creates room for private investment to be financed' (IMF 2003, p. 6). Fiscal austerity further reinforces the recovery of demand (and particularly investment) by the private sector, since it leads to a 'quick return of investors' confidence and a rapid pickup in growth' (ibid., p. 111). In this view, fiscal austerity tends to be expansionary (after perhaps a short transition period), even if it takes place during severe recessions. The logic is not different from that of the "crowding out' hypothesis, in which an expansion of fiscal spending reduces private expenditure 


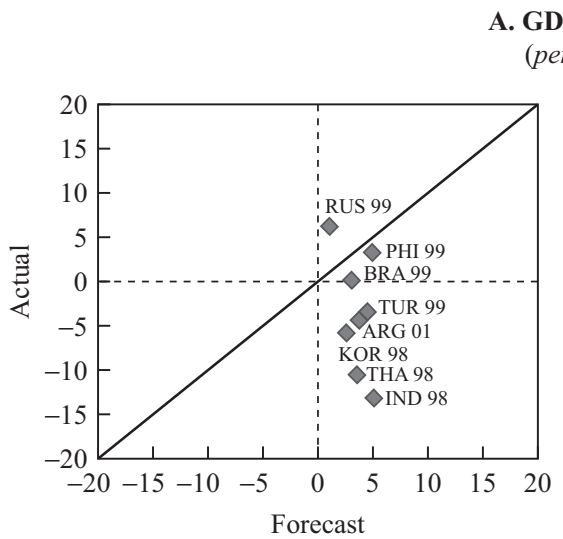

A. GDP growth

(per cent)

B. General government balance (per cent of $G D P$ )
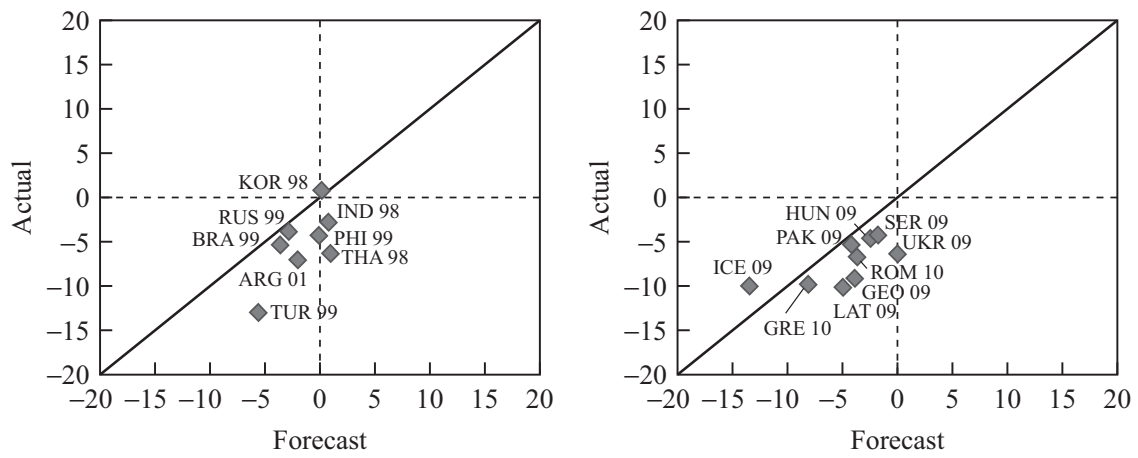

Notes: Adapted from UNCTAD 2011.

Source: IMF, Letter of Intent, available at: http://www.imf.org/external/np/cpid/default.aspx; and UNCTAD Globstat.

\section{Figure 1 Comparison between forecasts of GDP growth and fiscal balances in IMF-sponsored programmes and actual values for selected countries}

and fails to stimulate the economy. As public raising or lowering of spending are quickly matched by changes in private sector expenditure, higher public spending is at best irrelevant and fiscal austerity does not involve any significant cost; on the contrary, as it boosts investors' confidence, austerity may lead to an 'expansionary fiscal contraction'.

These views greatly overestimate the 'animal spirits' of the private sector and underestimate the consequences of pro-cyclical policies in the midst of a recession. They do not consider the risk of a downward spiral (in which many developing countries were stuck for many years): the contraction of domestic demand and employment in the short run is not easily reversed, and involves economic recession and lower investment ratios that reinforce each other and condemn many to a poverty trap. By ostensibly focusing on the confidence of financial agents, such policies deepen economic recessions and undermine the confidence of consumers, entrepreneurs and citizens in general, which is hardly the best way for recovering the confidence of financial agents. 


\section{MORE INSTRUMENTS FOR DIFFERENT POLICIES}

Most governments in advanced economies and international financial institutions assume there is very little room for manoeuver in stimulating the economy. The room for more supportive monetary policies seems limited by the already very low policy interest rates, while 'unconventional' measures such as quantitative easing proved to be ineffective for restarting credit to the private sector. And on the fiscal side, governments refrain from new stimulus that could send a signal of departure from the path to fiscal consolidation. Such a signal would spoil in their view all the advances made in the struggle for confidence; it would increase the risk premium on the sovereign debt of several countries, which could lead to their insolvency. The focus is increasingly put on structural reforms, which are supposed to boost competitiveness and resume growth.

These views are too optimistic and too pessimistic at the same time. They are overly optimistic in that they rely on a renaissance of confidence and/or on the virtues of structural reforms for restarting growth. Financial markets are pro-cyclical, and recent financial crises have shown that the recovery of confidence and of voluntary private capital inflows have always been the result of economic recovery, never their precondition. Furthermore, structural reforms cannot be a substitute for supportive macroeconomic policies for regaining economic growth, not only because they take time, but also because they may not deliver the expected results, especially if applied in the midst of a recession. For instance, introducing more flexibility in the labour markets and increasing the participation rate (a specific goal for several governments) while there is no increase in the demand for labour will only augment unemployment and depress wages and domestic demand, which is precisely the opposite that is needed. As weakening private demand and fiscal tightening tend to depress growth and fiscal revenues, 'fiscal consolidation' will remain elusive. If the answer is further fiscal tightening, a downward spiral of falling growth and fiscal revenues can be set in motion.

On the other hand, this approach is simultaneously too pessimistic with regard to the policy space available to governments. Fiscal space should not be seen as a given stock that depletes with use: indeed, if used properly, it can be expanded. Furthermore, it is possible to increase the multiplier effect of fiscal policies by modifying the composition of fiscal revenues and expenditure. In our garden of forking paths, it is possible to make different choices in the level and composition of fiscal revenues and expenditure to reintroduce a fiscal stimulus without necessarily increasing the current deficit. Higher deficits are not always a synonym for economic stimulus: they may result from lowering commodity prices in exporting countries, higher interest payments on the public debt, financial rescue packages or lowering taxes to the rich, all of which provide very little stimulus, if any, to domestic demand. On the other hand, fiscal measures may stimulate the economy without widening deficits; for example, public investment in infrastructure, subsidies for encouraging private investment and revenue transfers to the poor have high multiplier effects for economic activity and, consequently, for fiscal revenue. In other terms, fiscal multipliers (that is, the overall effect of a change in fiscal spending or taxation on GDP growth) depend strongly on the content of the fiscal package and also on the macroeconomic framework in which it takes place: multipliers are normally higher in economies with high unemployment and large unused production capacities. A review of recent studies on multipliers found that expansionary fiscal policy has a positive and significant effect on the level of economic activity; that spending multipliers are larger than tax cut multipliers; and that tax cuts benefiting lower-income households have a stronger effect than those benefiting high-income households 
(UNCTAD 2011, Box 3.2). Even the IMF has recently admitted that fiscal adjustments may have large negative impacts on activity, because fiscal multipliers may be quite large during recessions, when 'the traditional crowding-out argument is less applicable' (IMF 2012b, p. 34). A logical conclusion would be to take profit from these high multipliers for reviving growth through an expansionary fiscal policy: this would generate new fiscal revenues and eventually reduce the public debt-to-GDP ratio. The IMF does not go so far: it just recommends applying a gradual fiscal adjustment that would hurt growth less than an up-front restrictive fiscal shock (ibid., p. 36). ${ }^{1}$

Other instruments are also available in governments' policy tool box. Monetary policy can still be used, by better targeting the orientation of credit and promoting its use for easing low and medium income households' debt overhang. The attention should be less on the global amount of money issued and more on who gets the money and how they use it. Credit should be oriented towards agents that use them for increasing investment and demand. Finally, incomes policy is another policy tool that may be used for recovering domestic demand. One of the main causes of the crisis has been the growing inequality in income distribution in many countries (Attali 2008; Galbraith 2012), which resulted from deteriorating labour market conditions and wages growing at a slower rate than productivity. For many households, ever-increasing debt was the only way to expand, or even maintain, their consumption levels. Incomes policies aimed at reversing the declining trend in the wage share of national income may provide a decisive stimulus to demand and restart growth.

Given the strong interdependence among the major economies, blatantly revealed by the crisis, the outcome of supportive policies depends to a large extent on whether they take a coordinated or uncoordinated approach. For expansionary policies to be successful, a cooperative approach among the main partners is necessary. By the same token, the coordinated fiscal retrenchment applied in several systematically important countries at the same time potentiates its contractionary effect and undermines the chances for attaining fiscal consolidation.

Something similar is happening with 'structural reforms' aimed at boosting competitiveness through the reduction of the labour costs. This is a strategy that can work in some countries as long as it is accepted by their trading partners, but cannot be a general recipe for success: as competitiveness is a relative concept, all countries cannot improve their competitiveness at the same time. Germany, for instance, strongly improved its competitiveness in the 2000s vis-à-vis its European partners by containing the rise of its domestic prices below the target followed by the rest of the Euro area ('below, but close to, 2 per cent' ${ }^{2}$ ); at the same time, other members of the Euro area exceeded the inflation target, and these diverging trends explain a large part of the intra-zone imbalances. At present, uncompetitive countries are being asked to imitate Germany's strategy for recovering its competitiveness. The problem is that for improving some countries' competitiveness, other countries among their trade partners must

1. In the same report, the IMF has accepted some flexibility in the path towards fiscal consolidation, insofar as it does not change the course. In addition, it is only advised to countries with fiscal space; in such countries, 'the pace of near-term fiscal adjustment should be calibrated to avoid undue pressures on activity and employment'. This short-term flexibility must be framed into 'credible medium-term adjustment plans' and applied 'without undermining fiscal sustainability' (IMF 2012b, p. ix).

2. From the European Central Bank's homepage, which states: 'The primary objective of the ECB's monetary policy is to maintain price stability. The ECB aims at inflation rates of below, but close to, $2 \%$ over the medium term.' Available at: http://www.ecb.int/mopo/html/index.en.html. 
accept losing part of theirs, and Germany has already refused. This situation appears as an inextricable conundrum: most European countries are asked to increase their competitiveness; two-thirds of their exports go to other members of the European Union; but no member of the Union is willing to accept losing any competitiveness, which they could do, for instance, by allowing prices and wages to rise well above the regional average. Hence, deficit economies are vowed to price and wage deflation, which are extremely costly in terms of economic activity and can further increase the risks of widespread insolvency. In the end, it is very likely that the strategy will deliver neither growth nor competitiveness: with cuts in education, research and investments in infrastructure, the hypothetical gains that might be made through 'internal devaluation' will be outweighed by deteriorating production capacities.

In conclusion, fiscal austerity and wage compression have become part of the problem, not of the solution. This does not mean that fiscal discipline is not important or fiscal consolidation is not desirable, but the first must be exercised within a global programme for restarting growth, and the second will be the medium- to long-term result of that process, not its precondition. There are enough instruments for pursuing progrowth policies, although they must go beyond the macroeconomics of big aggregates (for example, fiscal balances and monetary aggregates) and intervene in the level and composition of fiscal expenditure and revenues, in the direction of credit and in the distribution of income. Instruments, including specific structural and institutional reforms, must also be better suited to their goals. To avert sovereign debt crisis, a lender of last resort is the best way to eliminate the risk of default and maintain risk premium and interest rates at manageable levels; instead, new doses of austerity would only deepen the recession and further deteriorate long-run solvency. In the Euro Zone, which appears today to be at the epicentre of the international crisis, the solution will not come from more fiscal tightening or the dismantling of the welfare state, but rather from deeper fiscal and financial integration and a cooperative approach to economic rebalancing (Aglietta 2012).

Finally, regional and international coordination are of vital importance, but not any kind of coordination. The call for general austerity, if listened to, would only make things worse. It is also important to discontinue the traditional asymmetric adjustment that throws the entire burden to deficit countries - with the exception of those that can issue an internationally accepted currency. For deficit countries avoiding self-defeating austerity and being able to search for ways to stimulate their economies, surplus economies must contribute by leading the expansionary response to the global crisis.

\section{REFERENCES}

Aglietta, Michel (2011). Ne pas confondre symptômes et maladie. In: Lorenzi, J.-H., ed. A la Recherche de la Nouvelle Croissance. Paris: Le Cercle des Economistes, Descartes \& Cie. Aglietta, Michel (2012). Zone Euro, Eclatement ou Fédération. Paris: Michalon Editions.

Attali, J. (2008). La Crise et Après. Paris: Fayard.

Bornhorst, F., Budina, N., Callegari, G., ElGanainy, A., Gomez Sirera, R., Lemgruber, A., Achaeschter, A. and Beom Shin, J. (2010). A status update on fiscal exit strategies. IMF Working Paper WP/10/272. Washington, DC: International Monetary Fund.

Bresser-Pereira, Luiz Carlos (2001). Incompetência e confidence building or trás de 20 anos de quase estagnaçao da America Latina. Revista de Economia Política, 21 (1): 141-166.

Fisher, I. (1933). The debt-deflation theory of great depressions. Econometrica, 1 (4): 337-357.

Galbraith, J. (2012). Inequality and Instability. Oxford and New York: Oxford University Press. 
36 Review of Keynesian Economics, Inaugural Issue

G20 (2010). Toronto summit declaration, 27 June. Available at: http://www.g20.utoronto.ca/ 2010/to-communique.html.

G20 (2011). Cannes action plan for growth and jobs, 4 November. Available at: www.economics ummits.info/2011/11/g20-cannes-summit-communique-declaration-and-action-plan/.

IMF (2001). Conditionality in fund-supported programs - policy issues. 16 February.

IMF (2003). Evaluation report: fiscal adjustment in IMF-supported programmes. Washington, DC: Independent Evaluation Office.

IMF (2010a). Fiscal Monitor. Washington, DC, May.

IMF (2010b). World Economic Outlook. Washington, DC, October.

IMF (2011a). Fiscal Monitor. Washington, DC, April.

IMF (2012a). Growth resuming, dangers remain. World Economic Outlook. Washington, DC, April.

IMF (2012b). Fiscal Monitor. Balancing Fiscal Policy Risks. Washington, DC, April.

Koo, Richard (2011). The world in balance sheet recession: causes, cure and politics. RealWorld Economic Review, 58.

Krugman, P. (1998). The confidence game. How Washington worsened Asia's crash. The New Republic, October.

Krugman, P. (2012). End This Depression Now! New York: W. W. Northon and Co.

Mussa, Michael and Sevastano, Miguel (1999). The IMF approach to economic stabilization. IMF Working Paper WP/99/104, July.

OECD (2011). Restoring Public Finances. Journal on Budgeting, 2.

Ostry, J., Ghosh, A., Kim, J. and Qureshi, M. (2010). Fiscal space. IMF Staff position Note, SPN/10/11, 1 September. Washington, DC: International Monetary Fund.

UNCTAD (2008-2012). Trade and Development Report (TDR). New York and Geneva.

UNDESA/UNCTAD/Regional Commissions (2008-2012). World Economic Situation and Prospects (WESP). New York. 